\title{
On the Chromophore of the Ninhydrin-Amino Acid Color Reaction
}

\author{
F. Dietz*, K. Rommel-Möhle, A. Schleitzer, N. Tyutyulkov ${ }^{+}$ \\ Fachbereich Chemie, Universität Leipzig, Talstraße 35, D-04103 Leipzig, Deutschland \\ Z. Naturforsch. 48b, 1133-1137 (1993); received February 19, 1993 \\ Ninhydrin-Amino Acid Color Reaction, Ruhemann's Purple, Cyclopentadienyl Cation, \\ Chromophore, Antiaromaticity \\ The long-wavelength absorption of the dye formed at the ninhydrin-amino acid color reac- \\ tion is caused by the anion (enolate) of diketohydrindamine-diketohydrindylidene (Ruhe- \\ mann's purple). Using the results of quantum-chemical calculations (MNDO, PPP) the basic \\ chromophoric system was identified as two coupled five-membered rings which have partial \\ anti-aromatic character like the antiaromatic cyclopentadienyl cation.
}

\section{Introduction}

One possibility for a qualitative identification and the photometric determination of amino acids is the reaction with ninhydrin $\mathbf{1}$ forming a blue colored dye (Ruhemann's purple) [1]. The reaction mechanism is well-known [2], but for the structure of the formed dye different isomeric species $\mathbf{2}$ (e.g. [3]), 3 (e.g. [4]), and 4 (e.g. [5]) are formulated in

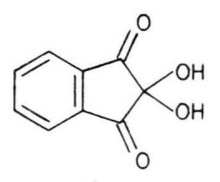

1
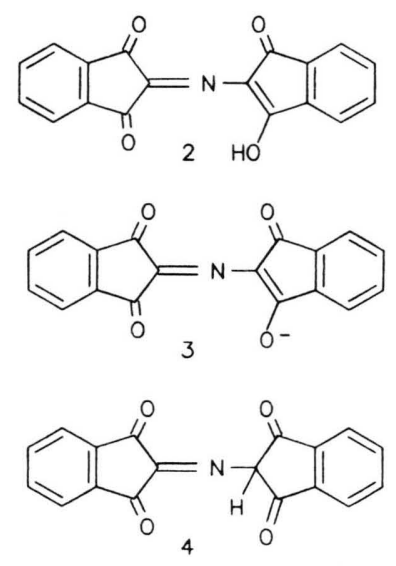

\footnotetext{
+ Permanent address: Bulgarian Academy of Sciences, Institute of Organic Chemistry, BG 1040 Sofia, Bulgaria

* Reprint requests please to F. Dietz, Fachbereich Chemie, Universität Leipzig, Talstraße 35, D-04103 Leipzig
}

Verlag der Zeitschrift für Naturforschung, D-72072 Tübingen

0932-0776/93/0800-1133/\$01.00/0 various lecture books of chemistry and biochemistry.

D. C. Wigfield et al. [6] have recently confirmed the structure 3 for Ruhemann's purple by means of ${ }^{1} \mathrm{H}$ NMR and ${ }^{13} \mathrm{C}$ NMR spectroscopy, but the long-wavelength absorption at $\lambda=570 \mathrm{~nm}$ seems to be unusual for the proposed dye structure. At first glance the chromophoric system of the dye cannot be identified.

The aim of this paper is to attach the chromophore to the dye structure. We propose that the conjugated five-membered rings having partial anti-aromatic character cause the unusual longwavelength absorption.

In former papers [7-10] we have presented our investigations on colored compounds with an antiaromatic cyclopentadienyl cation (CPC) fragment as the basic chromophore. The following characteristic features serve as criteria for the qualitative and quantitative judgement of the anti-aromaticity of an organic compound [7-10]:

(i) Anti-aromatic systems have extremely small excitation energies, and therefore they absorb at long wavelengths.

A perturbation of an anti-aromatic $\pi$-electron system, e.g. by extension of the conjugated system, is connected with a blue shift of the longest-wavelength absorption, in contrast to aromatic compounds, where a red shift is observed.

(ii) The geometric configuration of anti-aromatic structures is characterized by an alternation of bond distances and anomalous lengths $\mathrm{R}$ of some bonds (in typical cases R>150 pm).

(iii) The sum of the net $\pi$-electron charges $(\mathrm{Q}(\pi))$ at the atoms $\mu$ forming a five-membered ring can be compared with $\mathrm{Q}(\pi)$ of the $\mathrm{CPC}(\mathrm{Q}(\pi)=1)$ :

$$
\mathrm{Q}(\pi)=5-\sum_{\mu=1}^{5} \mathrm{q}_{\mu}
$$


This can serve as an additional criterion for complex structures containing a CPC fragment.

Especially because of (i), if one can show the presence of an anti-aromatic structure element within a certain compound, it is to be supposed that this part of the molecule will act as the basic chromophore.

In this paper, we have studied three different proposed structures of Ruhemann's Purple ( 2 to 4 ) and calculated their geometric parameters and electronic structures in order to identify the basic chromophore of the dye of the ninhydrin-amino acid color reaction. Additionally, taking into consideration the criterion (i), we calculated the electronic spectra of related structures 5 to $\mathbf{9}$ with a shortened $\pi$-electron system.
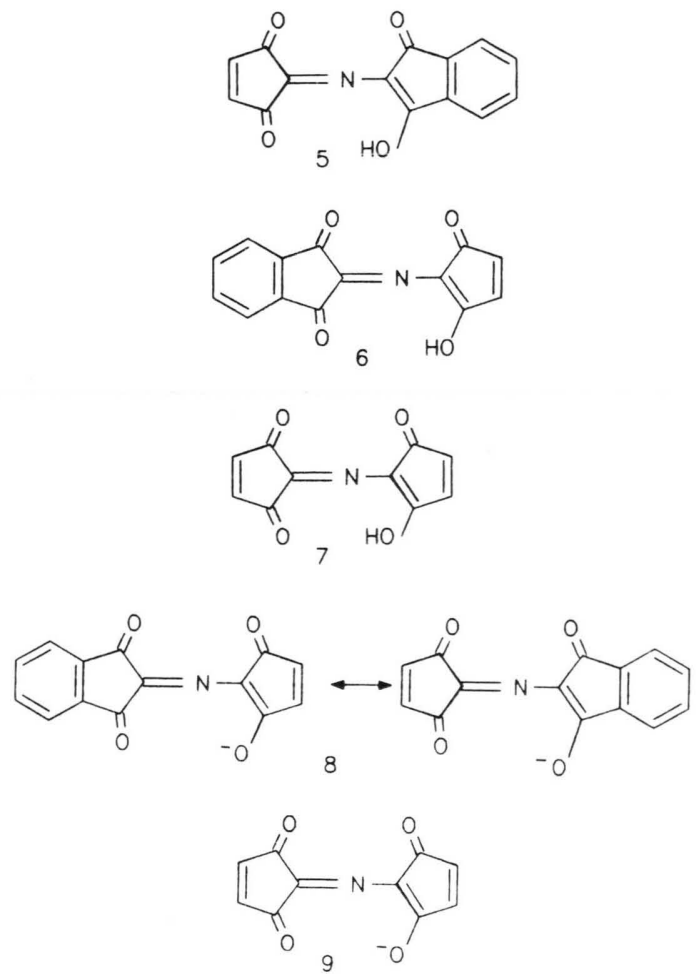

\section{Computational Methods}

The results of the investigations were obtained with different quantum-chemical methods: the molecular geometries were optimized in relation to their most stable structure using the semi-empirical all-valence electron method MNDO (Modified Neglect of Differential Overlap) [11]. Based on these most stable geometries the electron excitation energies and intensities (oscillator strengths) have been calculated by the PPP (Pariser Parr Pople) procedure in $\pi$-electron approximation [12]. The following atomic parameters [13] have been used:

C: VSIP (Valence State Ionization Potential) $=$ $11.42 \mathrm{eV}$; EA (Electron Affinity) $=0.58 \mathrm{eV}, \mathrm{Z}$ $($ core charge $)=1 ; \mathrm{O}$ (carbonyl oxygen $)$ : VSIP $=$ $17.28 \mathrm{eV}, \mathrm{EA}=2.7 \mathrm{eV}, \mathrm{Z}=1$; O (hydroxyl oxygen): $\operatorname{VSIP}=27.17 \mathrm{eV}, \mathrm{EA}=12.59 \mathrm{eV}, \mathrm{Z}=2 ; \mathrm{O}$ (enolate) [14]: VSIP $=18.12 \mathrm{eV}, \mathrm{EA}=3.6 \mathrm{eV}$, $\mathrm{Z}=1$.

Equal parameters have been used for the four oxygen atoms within the enolate structures $\mathbf{3 , 8}$ and 9.

\section{Results and Discussion}

\subsection{The chromophore of Ruhemann's purple}

The most probable structure of the blue-colored Ruhemann's purple is the enolate $\mathbf{3}$ which is one of four equivalent mesomeric structures $[6,15]$. This structure contains an indandione-1,3-enolate fragment. In a former paper [9] we have shown that the red color of indandione-1,3-enolate is caused by the five-membered ring which has anti-aromatic character.

The color of indigo and of indigo derivatives has been explained in the same way by the two linked five-membered rings which have partial anti-aromatic character [10]. Some specific properties of the indigoid dyes, e.g. the blue shift at elongation of the conjugated $\pi$-electron system, can be explained only with the anti-aromatic character of the coupled five-membered rings.

These arguments are indications that the basic chromophore of Ruhemann's purple should be the two five-membered rings connected by a nitrogen atom which have partial anti-aromatic character. Using the criteria for anti-aromatic character of conjugated five-membered rings formulated in the introduction we will prove this assumption in the following.

\subsection{Absorption spectra and electronic structure}

Corresponding to criterion (i) the small excitation energy of the longest-wavelength $\pi, \pi^{*}$ transition of Ruhemann's purple is caused by the anti- 
aromatic character of the five-membered rings as the chromophoric system.

The experimental $\left(\Delta \mathrm{E}_{\text {exp }}\right)$ and calculated $\left(\Delta \mathrm{E}_{\text {calc }}\right)$ transition energies, the experimental intensities $(\lg \varepsilon)$, and the calculated oscillator strengths (f) of structures $\mathbf{2 , 3}$, and $\mathbf{4}$ are given in Table I.

Table I. Experimental $\left(\Delta \mathrm{E}_{\exp }\right.$ in $\left.\mathrm{nm}\right)$ and calculated $\left(\Delta \mathrm{E}_{\text {calc }}\right.$ in $\left.\mathrm{nm}\right)$ wavelengths and experimental $(\lg \varepsilon)$ and calculated (oscillator strengths $f$ ) intensities of the absorption maxima of structures $\mathbf{2}$ to $\mathbf{9}$, and sums of the $\pi$ net charges of the five-membered rings $(\mathrm{Q}(\pi))$ of the enol fragments calculated by the PPP procedure.

\begin{tabular}{llllll}
\hline Compound & $\Delta \mathrm{E}_{\text {exp }}$ & $\lg \varepsilon$ & $\Delta \mathrm{E}_{\text {calc }}$ & $\mathrm{f}$ & $\mathrm{Q}(\pi)$ \\
\hline $\mathbf{2}$ & 490 & 4.36 & 484 & 0.36 & 0.224 \\
& 400 & 4.28 & 391 & 0.34 & \\
$\mathbf{3}$ & 252 & 5.19 & 257 & 0.43 & \\
& 570 & 4.39 & 526 & 0.05 & 0.440 \\
$\mathbf{4}$ & 400 & 4.39 & 458 & 0.87 & \\
$\mathbf{5}$ & 252 & 4.70 & 253 & 0.36 & \\
$\mathbf{6}$ & - & - & 304 & 0.01 & \\
$\mathbf{7}$ & - & - & 480 & 0.26 & 0.207 \\
$\mathbf{8}$ & - & - & 616 & 0.11 & 0.239 \\
$\mathbf{9}$ & - & - & 622 & 0.08 & 0.237 \\
\hline
\end{tabular}

To explain the absorption spectrum of Ruhemann's purple the transition energies were calculated with the PPP procedure using the optimized geometry of structure 3 . The calculated transition energies are in fairly good agreement with the experimental absorption maxima [15] (see Table I).

The longest-wavelength absorption shows a significant solvent effect. In pure nonaqueous solvents the maximum is located in the range from $550 \mathrm{~nm}$ (in pyridine) to $605 \mathrm{~nm}$ (in DMSO) [16].

The calculated absorption maxima and intensities of the enol 2 correspond very well to the experimental absorption wavelengths of the diketohydrindamine-diketohydrindylidene $\cdot 2 \mathrm{H}_{2} \mathrm{O}$ in chloroform or in benzene described by MacFadyen [15].

The most significant indication of an anti-aromatic character of the five-membered rings besides the small excitation energies is the spectral shift at perturbation of the $\pi$-electron system. To check this characteristic feature we have investigated the structures $\mathbf{5}$ to $\mathbf{7}$, and $\mathbf{8}$ and $\mathbf{9}$ with smaller $\pi$-electron systems in relation to $\mathbf{2}$ and $\mathbf{3}$, respectively. The calculated transition energies for these compounds are collected in Table I. The PPP calculations were carried out using the same atomic parameters like for structures $\mathbf{2}$ and $\mathbf{3}$, and MNDO optimized geometries.

In the case of structures $\mathbf{9 , 8}$, and $\mathbf{3}$ (Ruhemann's purple) the extension of the conjugated $\pi$-electron system results in a blue shift of the longest-wavelength absorption by more than $100 \mathrm{~nm}$. Because both ring systems are equivalent the both fivemembered rings should have a comparable significant anti-aromatic character. The two equivalent CPC fragments within the enolate structure 3 can be considered as the basic chromophore of Ruhemann's purple.

For the enol 2, the spectral shift in dependence on the extension of the $\pi$-electron system was studied with the structures $\mathbf{7 , 6}, \mathbf{5}$, and $\mathbf{2}$. In this order also a blue shift is observed. This means that especially the five-membered rings within the enol structure elements should have a partial anti-aromatic character which are the chromophore responsible for the long-wavelength absorption and the red color of the enol 2.

Structure $\mathbf{4}$ can be excluded from the discussion of the chromophore of the dye of the ninhydrinamino acid color reaction. This compound should absorb in the UV spectral region (see Table I) because the conjugated system is interrupted, and the five-membered rings have no anti-aromatic character.

\subsection{Molecular structure}

The geometries of $\mathbf{2}$ (symmetry group $\mathrm{C}_{1}$ ) and $\mathbf{3}$ (symmetry group $\mathrm{C}_{2}$ ) have been optimized for the most stable structure using the MNDO procedure. They are shown in Fig. 1. Both structures contain strongly distorted five-membered rings which are characterized by significant bond length alternation and certain anomalously long bonds $(\mathrm{R}>150$ $\mathrm{pm})$ typical for substituted cyclopentadienyl cations with anti-aromatic character. This distortion is caused by a pseudo-Jahn-Teller effect [17]. The central $\mathrm{C}-\mathrm{N}-\mathrm{C}$ bond angle is increased to about $127^{\circ}(2)$ and $129^{\circ}(3)$, respectively.

The both ring systems are twisted against each other by a torsion angle of $44^{\circ}$ (structure 2 ) and 


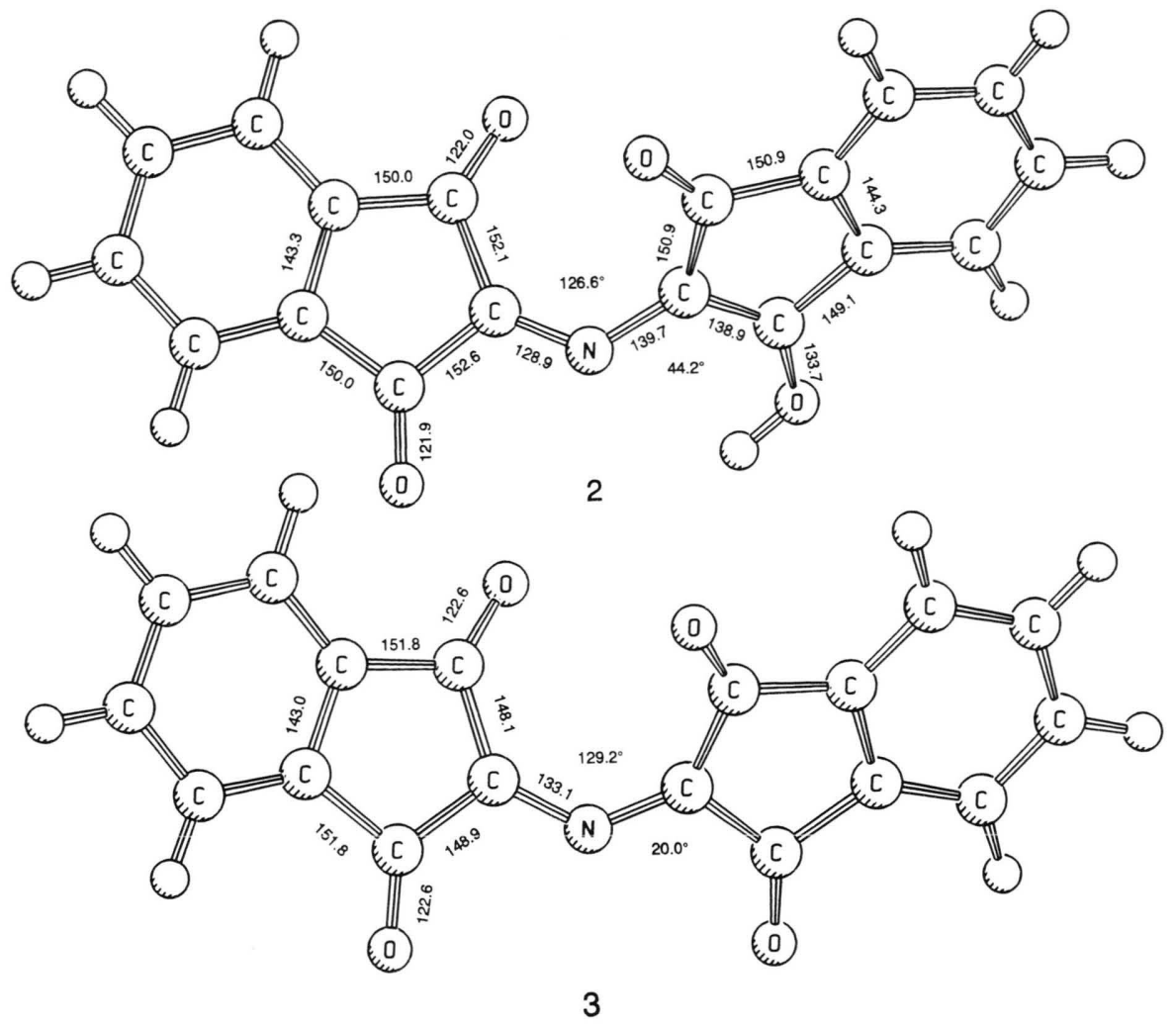

Fig. 1. Optimized geometries of the molecular structures [18] of the diketohydrindamine-diketohydrindylidene enol 2 and of Ruhemann's purple 3 (MNDO calculation). about $20^{\circ}$ in the enolate 3 . In the case of $\mathbf{3}$ both conjugated $\pi$-electron ring systems are equivalent and therefore the electronic structure of $\mathbf{3}$ can be described by four equivalent mesomeric structures [15].

\subsection{Electronic structure}

The third argument, corresponding to criterion (iii), for an anti-aromatic character of the fivemembered rings in complex molecular structures is the positive charge of the ring (see eq. 1 ). $\mathrm{Q}(\pi)$ of the structures 2 to 9 calculated by the PPP procedure are summarized in Table I.

The values are approximately indirect proportional to the excitation energies: the greater $\mathrm{Q}(\pi)$ the smaller are the excitation energies (the greater is the value of the longest-wavelength absorption), and the stronger is the anti-aromatic character of the five-membered rings within the enol or enolate fragments of structures $2,3,5$, to 9 .

\section{Conclusion}

The diketohyrindamine-diketohydrindylidene enolate 3 was confirmed as the structure of Ruhemann's purple which is the dye of the ninhydrinamino acid color reaction. The basic chromophore of Ruhemann's purple can be explained with the anti-aromatic character of the coupled five-membered rings.

The chromophoric system of the enol 2 which absorbs at somewhat shorter wavelengths (485 $\mathrm{nm}$, red color) is the five-membered ring within the indandione-1,3-enol fragment which has also partial anti-aromatic character.

Both molecules $\mathbf{2}$ and $\mathbf{3}$ are non-planar. The ring fragments are twisted against each other by about $44^{\circ}(2)$ and $20^{\circ}$ (3).

Financial support of the Fonds der Chemischen Industrie (F.D.) and the Alexander von Humboldt-Stiftung (N.T.) is gratefully acknowledged. A.S. thanks the Studienstiftung des Deutschen Volkes for a scholarship. 
[1] B. Kakak, Z. J. Vejdelekc, Handbuch der photometrischen Analyse organischer Verbindungen, Vol. II, p. 1005, Verlag Chemie, Weinheim (1974).

[2] D. J. McCaldin, Chem. Rev. 60, 39 (1960).

[3] S. H. Pine, J. B. Hendrickson, D. J. Cram, G. S. Hammond, Organic Chemistry, McGraw-Hill Book Company, 4th ed., New York (1980).

[4] A. L. Lehninger, Biochemie, 2. Auflage, Verlag Chemie, Weinheim (1987).

[5] H. R. Mahler, E. H. Cordes, Biological Chemistry, Harper \& Row Publ., second ed., New York (1966).

[6] D. C. Wigfield, G. W. Buchanan, S. M. Croteau, Can. J. Chem. 58, 201 (1980).

[7] F. Dietz, N. Tyutyulkov, M. Rabinovitz, J. Chem. Soc., Perkin II 1993, 157.

[8] F. Dietz, N. Tyutyulkov, A. Tadjer, J. Inform. Record. Mat. 17, 251 (1989).
[9] N. Tyutyulkov, M. Tasseva, E. Georgiev, J. Prakt. Chem. 329, 780 (1987).

[10] N. Tyutyulkov, G. Olbrich, F. Dietz, J. Inform. Record. Mat. 16, 431 (1988).

[11] J. J. P. Stewart, MOPAC 6.0, QCPE 455.

[12] H. Hartmann, PPP program system for PC, TH Merseburg.

[13] J. Fabian, Ber. Bunsenges. Phys. Chem. 73, 107 (1969).

[14] R. Radeglia, E. Gey, K.-D. Nolte, S. Dähne, J. Prakt. Chem. 312, 877 (1970).

[15] D. A. MacFadyen, J. Biol. Chem. 186, 1 (1950).

[16] M. Friedman, Mikrochem. J. 16, 204 (1971).

[17] W. T. Borden, E. R. Davidson, J. Am. Chem. Soc. 101, 377 (1979).

[18] Drawing by Schakal 92. E. Keller, Kristallograph. Institut, Univers. Freiburg, Germany. 